\title{
KOMUNIKASI PERSUASIF DALAM MEMPERTAHANKAN LOYALITAS RELAWAN PADA KOMUNITAS SOSIAL
}

\author{
Kadiva Dwilia Rosadiputri, Maylanny Christin \\ Program Studi Ilmu Komunikasi, Fakultas Komunikasi dan Bisnis, Telkom University \\ Jl. Telekomunikasi Terusan Buah Batu, Bandung Jawa Barat 40257 \\ No. HP: 087822660014, 081320052708 \\ e-mail: kadivadwilia98@gmail.com, maylannychristin@gmail.com
}

\author{
Naskah diterima tanggal 13 Februari 2020 direvisi tanggal 24 Maret 2021 disetujui \\ tanggal 1 April 2021
}

\begin{abstract}
Abstrak
Komunikasi persuasif merupakan bagian yang berperan penting dalam jalannya sebuah komunitas. Komunitas tidak akan bertahan jika anggota didalamnya tidak mempertahankan loyalitas yang menjadi bentuk kontribusi anggota kepada komunitas. Untuk mempertahankan loyalitas anggota komunitas, dibutuhkan upaya dalam melibatkan hubungan antara berbagai unsur komunikasi persuasif. Penelitian ini bertujuan untuk membahas mengenai komunikasi persuasif dalam mempertahankan relawan komunitas sosial Sebung Bandung. Komunitas yang sudah berjalan selama 3 tahun ini, memiliki metode komunikasi persuasif dalam upaya mempertahankan relawan, yang secara rutin menggerakan aksi berbagi sebungkus nasi kepada tuna wisma dan kaum duafa. Lima teknik dalam metode komunikasi persuasif yang dilakukan pengurus Sebung Bandung terhadap relawannya yaitu rational persuasion, consultation tactics, ingratiation tactics, personal appeals tactics, dan exchange tactics. Penelitian ini menerapkan teknik pengumpulan data dengan observasi partisipatif, wawancara semi terstruktur, dan dokumentasi. Wawancara dilakukan dengan tujuh narasumber yaitu satu informan kunci, lima informan utama, dan satu informan ahli. Hasil penelitian menunjukan kelima teknik komunikasi persuasif diterapkan kepada seluruh rangkaian kegiatan mingguan Sebung yaitu briefing, turun ke jalan, sharing session, dan acara bebas, yang membentuk sense of community pada relawan komunitas, sehingga timbul keinginan untuk berpartisipasi dalam setiap kegiatan Sebung Bandung. Pada akhirnya terbentuklah loyalitas relawan yang ditunjukan oleh keinginan relawan untuk bertahan dalam komunitas Sebung Bandung.
\end{abstract}

Kata-kata kunci: Komunikasi; Komunitas; Loyalitas; Persuasif; Relawan

\begin{abstract}
Persuasive communication is a part that plays an important role in the course of a community. The community will not survive if the members do not maintain loyalty which is a form of member contribution to the community. To maintain the loyalty of community members, efforts are needed in engaging relationships among various elements of persuasive communication. This study aims to discuss persuasive communication in maintaining social community volunteers in Sebung Bandung. The community, which has been running for 3 years, has persuasive communication methods in its efforts to retain volunteers; it routinely mobilizes the sharing of a packet of rice to the homeless and the poor. The five techniques in the persuasive communication methods carried out by Sebung Bandung's management of volunteers are rational persuasion, consultation tactics, ingratiation tactics, personal appeals tactics, and exchange tactics. This study applies data collection techniques namely participatory observation, semi-structured interviews, and documentation. Interviews were conducted with seven sources, namely one key informant, five key informants, and one expert informant. The results showed that the five persuasive communication techniques were applied to the entire series of Sebung's weekly activities, namely briefings, going to the streets, sharing sessions, and free events, which formed a sense of community in community volunteers, thus arising a desire to participate in every Sebung Bandung activity. In the end, volunteer loyalty was formed, which was shown by volunteers' desire to stay in the Sebung Bandung community.
\end{abstract}


Jurnal Komunikasi Universitas Garut: Hasil Pemikiran dan Penelitian

Vol. 7, No. 1, April 2021

Halaman 606-616

Keywords: Communication; Community; Loyalty; Persuasive; Volunteer

\section{Pendahuluan}

Komunitas merupakan sekumpulan orang yang terbentuk atas dasar persamaan dan akan hilang jika tujuan yang telah disepakati sebelumnya sudah tidak sama dan tidak kuat lagi. Bandung merupakan salah satu kota besar yang menampung beragam komunitas dengan segala keunikannya. Ridwan Kamil sebagai Wali Kota Bandung tahun 2016 menyebutkan setidaknya terdapat 5000 komunitas di Bandung mulai dari komunitas ekonomi, lingkungan, sosial dan hobby yang terbentuk karena kultur warga Bandung yang gemar berkumpul (https://bandung.merdeka.com). Salah satu komunitas kategori non-profit berada pada komunitas sosial kemanusiaan. Berlandaskan tujuan berbuat kebaikan, mereka terbentuk dan melakukan kegiatan yang telah disepakati sebelumnya.

Sebung (Sego Bungkus) Bandung yang berarti nasi bungkus merupakan salah satu komunitas yang bergerak dibidang sosial kemanusiaan. Berdiri sejak tahun 2017, kegiatan utama komunitas ini yaitu membagikan "Nasi Bungkus" kepada tuna wisma dan kaum duafa. Kegiatan Sebung Bandung dilakukan satu minggu sekali pada hari Jumat malam pukul 20.00 WIB. Keberlangsungan komunitas ini didasari oleh konsistensi penggerak Sebung Bandung yang hadir pada setiap hari jumat untuk turun ke jalan dan membagikan sebungkus nasi. Penggerak Sebung Bandung merupakan relawan yang bergerak aktif untuk turun kejalan dan membagikan nasi pada kegiatan rutin Sebung. Relawan tersebut didominasi oleh anak muda berusia 18 hingga 24 tahun.

Bermodalkan tujuan dan nilai yang sama, tidak cukup untuk mempertahankan massa dalam suatu komunitas. Thackray dalam Leksono (2014) mengatakan kebosanan dalam kegiatan yang monoton secara luas diakui sebagai efek samping yang tidak diinginkan karena kebosanan dalam mengerjakan kegiatan yang berulang-ulang. Kegiatan mingguan yang selalu sama dan berlangsung selama tiga tahun, dapat menimbulkan kejenuhan bagi relawan yang bergerak turun kejalan. Jika relawan tidak ada, maka komunitas tersebut tidak akan berlangsung lama. Dibutuhkan sebuah strategi persuasif yang dikomunikasikan oleh pengurus komunitas, agar relawan tersebut tidak menemui kejenuhan dalam rutinitas kegiatan didalamnya.

Sebung Bandung yang merupakan cabang dari Sebung Surabaya memiliki fokus yang berbeda. Mereka menekankan bahwa treatment yang diberikan oleh pengurus tidak fokus kepada target Sebung, namun kepada relawan yang menjadi penggerak aktif Sebung Bandung. Pengurus Sebung menerapkan komunikasi persuasif pada seluruh rangkaian kegiatan Sebung yaitu briefing, turun ke jalan (greetings), sharing session, serta acara bebas. Hal tersebut akan memunculkan sikap loyal sehingga anggota akan tetap bertahan dalam komunitas, meskipun komunitas tersebut mengalami kemajuan atau kemunduran (Nitisemito, 2013:135). Loyalitas relawan Sebung tersebut ditunjukan dengan kontribusi aktif untuk hadir disetiap kegiatan mingguan Sebung dan acara Sebung lainnya.

Komunitas sosial Sebung Bandung dipilih sebagai objek, dan komunikasi persuasif dalam mempertahankan loyalitas relawan komunitas tersebut sebagai topik yang dibahas, karena komunitas ini masih 
konsisten bergerak dengan relawan yang aktif berkontribusi sebagai penggerak dalam kegiatan rutin komunitas Sebung. Sementara selama 3 tahun berjalan, rangkaian kegiatan yang dilakukan relatif sama. Sebung Bandung sebagai komunitas sosial memiliki kewajiban mempertahankan relawannya dengan aktivitas persuasif yang diterapkan dalam berbagai aspek tertentu. Salah satunya meyediakan kebutuhan yang tidak mereka sadari.

Terdapat penelitian terdahulu yang membahas komunikasi persuasif komunitas kongkow nulis dalam meningkatkan budaya menulis dikalangan mahasiswa Kota Pekanbaru (Caroline, 2018). Hasil penelitian tersebut yaitu upaya yang dilakukan adalah dengan membangun kredibilitas dan pesan persuasif oleh komunitas, lalu menyediakan program dan treatment kepada komunitas untuk memiliki project yang output nya sebuah karya buku. Metode persuasif yang diterapkan pengurus komunitas adalah melalui kebutuhan kognitif mahasiswa, lifestyle dan emosional. Sebung Bandung sebagai komunitas sosial memiliki kewajiban mempertahankan relawannya dengan metode persuasif yang diterapkan dalam berbagai aspek tertentu.

Pemilihan metode persuasif sangat diperhatikan guna memudahkan komunitas tersebut untuk dapat mempertahankan retensi para penggerak atau relawan didalamnya. Dengan begitu komunitas tersebut dapat mendongkrak keberadaannya dan tidak tergerus oleh waktu. Adapun tujuan dari penelitian ini yaitu memahami implementasi komunikasi persuasif dalam mempertahankan loyalitas relawan pada komunitas sosial Sebung Bandung.

\section{Metode Penelitian}

Penelitian ini menggunakan jenis penelitian kualitatif dengan paradigma konstruktivisme. Penelitian ini berpandangan bahwa pengetahuan itu bukan hanya merupakan hasil pengalaman terhadap fakta, tetapi juga merupakan hasil konstruksi pemikiran subjek yang diteliti (Morissan, 2013:31). Penelitian ini memilih subjek komunikasi persuasif dalam mempertahankan loyalitas relawan pada komunitas sosial Sebung Bandung. Peneliti meneliti bagaimana aktivitas seluruh penggerak komunitas tersebut dalam melakukan komunikasi persuasif untuk menarik ketertarikan dan loyalitas relawan komunitas serta tempat dan lingkungan dimana terjadinya proses komunikasi persuasif antara pengurus, penggerak dan target komunitas sosial Sebung Bandung.

Objek penelitian dalam penelitian ini adalah penggerak komunitas meliputi pengurus serta relawan yang aktif pada kegiatan yang ada di komunitas Sebung Bandung. Peneliti memperinci objek penelitian ini dengan cara pengambilan informan yang terdiri dari informan kunci yaitu co-founder komunitas Sebung Bandung, informan utama yaitu 5 relawan aktif komunitas Sebung Bandung, serta informan ahli yaitu seorang pengamat sosial. Penelitian ini menerapkan teknikteknik pengumpulan data primer dan sekunder yaitu:

1) Observasi Partisipatif

Pengamatan berperan serta ini adalah satu teknik pengumpulan data yang dilakukan dengan cara interaksi langsung dengan subjek yang diamati, memperhatikan apa yang mereka lakukan, mendengarkan apa yang mereka katakan, serta mengikuti setiap aktivitas yang dikerjakan oleh subjek yang diteliti. Teknik observasi partisipatif digunakan untuk menghimpun data-data atau informasi yang bersifat lahiriah, sebagaimana karakteristik 
Jurnal Komunikasi Universitas Garut: Hasil Pemikiran dan Penelitian

Vol. 7, No. 1, April 2021

Halaman 606-616

observasi dengan memanfaatkan

keseluruhan panca indera (Ibrahim, 2015:84).

2) Wawancara Semi-Terstruktur

Pada wawancara semi-terstruktur peneliti hanya menyiapkan beberapa pertanyaan kunci untuk memandu jalannya proses tanya jawab wawancara. Pertanyaan yang disiapkan juga memiliki kemungkinan untuk dikembangkan dalam proses wawancara yang dilakukan (Ibrahim, 2015:89-90). Teknik ini dilakukan kepada seluruh informan meliputi informan kunci, informan utama serta informan tambahan.

\section{3) Dokumentasi}

Dokumen yang dimaksud sumber pengumpulan data dalam penelitian kualitatif adalah yang terkait dengan rekaman kejadian, proses, setting sosial mengenai peristiwa yang diteliti (Ibrahim, 2015:96).

Penelitian ini memilih triangulasi
sumber untuk mengecek dan membandingkan data dari berbagi sumber. Peneliti melakukan wawancara dengan informan utama yaitu relawan dari komunitas sosial Sebung Bandung yang tidak begitu saja diambil dan dianggap sebagai informasi yang benar. Lalu akan dibandingkan hasil wawancara antara informan utama satu dengan lainnya dan antara informan utama dengan informan kunci. Apabila saling berkesinambungan maka dapat ditarik kesimpulan dan hasil wawancara tersebut dapat dibuktikan kebenaran dan keabsahannya.

\section{Hasil Penelitian dan Pembahasan}

Berdasarkan data yang telah didapat, maka akan dijelaskan hasil dan pembahasan yang

dikaitkan dengan teori dan konsep yang relevan.

\section{Rational Persuasion}

Tindakan rasional menurut Weber berhubungan dengan pertimbangan yang sadar dan pilihan bahwa tindakan itu dinyatakan (Johnson, 2004: 220). Rational persuasion diimplementasikan pada rangkaian awal kegiatan Sebung mingguan yang berlangsung setiap hari Jum'at pukul 20.00 WIB di Taman Sejarah Balaikota Bandung. Kegiatan tersebut dipimpin oleh penanggung jawab yang biasanya diambil alih oleh founder dan co-founder Sebung Bandung. Mereka mengawali kegiatan tersebut dengan briefing yaitu pengenalan singkat mengenai komunitas Sebung meliputi awal didirikan, rangkaian kegiatan, dan tujuan komunitas Sebung itu sendiri. Dilanjut dengan pengenalan masing-masing relawan yang hadir serta arahan dalam melakukan rangkaian kegiatan selanjutnya. Seluruh penjelasan yang diucapkan oleh penanggung jawab selalu diiringi oleh pemberian data atau fakta yang menjadi alasan dari aturan atau hal yang wajib dilakukan relawan komunitas Sebung.

Data dan fakta tersebut didapati dari pengalaman penanggung jawab dalam mengelola program atau kegiatan sosial di tempat lain. Penanggung jawab yang menjadi pembicara dalam sesi briefing tersebut, memiliki dua kriteria penting yaitu kredibilitas dan attractiveness (interest, similarity, beauty). Tujuan utama saat briefing adalah menyampaikan sebuah keharusan relawan Sebung Bandung pada rangkaian kegiatan selanjutnya, untuk melakukan greetings dan pemberian motivasi kepada target yang dilakukan selama 10-15 menit. Hal tersebut merupakan bentuk implementasi secara nyata dari bagaimana pengurus Sebung 
melakukan komunikasi persuasif kepada relawannya. Maka greeting dan pemberian motivasi yang diarahi oleh pengurus Sebung kepada relawan menjadi langkah awal untuk membangun loyalitas relawan. Pengurus memberikan contoh serta mempersuasi dengan hal-hal yang mengarah pada makna sosial dan kemanusiaan.

\section{Consultation Tactics}

Dala Carnegie dalam Great Influencer (2018: 66) mengatakan bahwa rasa tertarik kepada lawan bicara dapat diaktualisasikan dengan berbagai cara. Pun dapat dengan ungkapan bahwa seseorang memang tertarik dengan kepribadian, pengalaman, kelebihan dan sebagainya. Hal tersebut ditunjukan pula dengan bahasa tubuh dan bentuk perhatian. Consultation Tactics diimplementasikan dalam beberapa rangkaian kegiatan Sebung yang salah satunya adalah sharing session. Pengurus memberikan sarana kepada relawan untuk dapat mengasah kemampuan berbicara didepan publik. Sesi ini dilakukan sepulang turun ke jalan di titik kumpul yaitu Taman Sejarah. Metode ini berupa sebuah aktivitas, dimana relawan berkesempatan untuk menceritakan pengalaman berbagi yang sudah dilakukan pada sesi turun kejalan. Sesi ini dipimpin langsung oleh pengurus Sebung yang menjadi penanggung jawab kegiatan.

Dengan membentuk sebuah wadah untuk mengembangkan kemampuan berbicara didepan pulik, relawan tidak hanya dapat mengasah softskill saja. Namun mereka memiliki beberapa kemampuan lainnya seperti:

\section{1) Public Speaking}

Relawan Sebung Bandung didominasi oleh masyarakat yang memiliki pribadi yang tertutup.
Dengan begitu Sebung menyediakan sesi sharing sebagai wadah bagi relawan untuk mengembangkan kemampuan berbicara didepan publik mengenai cerita yang mereka miliki. Cerita tersebut dapat berupa pengalaman satu relawan berkomunikasi dengan target atau pengalaman lain yang mereka dapatkan dikegiatan sosial serupa. Posisi duduk saat mereka melakukan sharing session adalah duduk melingkar dan posisi pembicara yang berdiri ditempat semula ia duduk.

2) Mendengar

$$
\text { Baik relawan maupun }
$$
pengurus menjadikan diri mereka sebagai pendengar yang baik atas orang-orang yang sedang berbicara saat sharing session. Sikap mendengarkan dari sisi pengurus dapat membangun suatu hubungan yang baik dengan relawan. Sementara dari sisi relawan akan meningkatkan wawasan dan pengetahuan mereka tentang sosial kemanusiaan. Maka akan terbangun loyalitas diantara relawan dan pengurus Sebung itu sendiri.

3) Empati

Baron dan Byrne dalam
(Asih dan Pratiwi, 2010)
menyatakan bahwa empati
merupakan kemampuan untuk
merasakan keadaan emosional
orang lain, merasa simpatik dan
mencoba menyelesaikan masalah
dengan mengambil perspektif orang
lain. Dengan mendengerakan pada
sharing session, relawan Sebung
akan belajar memahami isi cerita
dan menghargai perbedaan diantara


pembicara dan diri mereka masingmasing. Dengan begitu relawan Sebung dapat mengasah empati dari pertukaran cerita pada sharing tersebut.

4) Merubah Persepsi

Dengan adanya sesi sharing maka pengetahuan relawan semakin bertambah dan mereka mampu untuk menafsirkan kegiatan yang mereka lakukan dengan lingkup yang lebih luas.

\section{Ingratiation Tactics}

Lincoln dalam Great Influencer (2018:61) mengatakan disetiap suratnya bahwa, "Setiap Orang Menyukai Pujian", manusia memiliki hasrat untuk menjadi penting. Memberikan apresiasi merupakan salah satu strategi untuk mempertahankan loyalitas relawan. Apresiasi tersebut diterapkan diseluruh rangkaian kegiatan Sebung Bandung yaitu briefing hingga sharing session. Apresiasi yang dilakukan oleh Sebung kepada relawannya dibagi menjadi beberapa bentuk yaitu:

1) Pujian

Sebuah pujian bukan hal yang jarang dijumpai di komunitas Sebung. Pada saat briefing ada saat dimana mereka saling berkenalan dan memuji satu sama lain. Treatment ini menjadi lumrah karena diantara mereka sudah ringan untuk menyampaikan pujian. Dengan begitu pada saat turun kejalan, relawan juga menerapkan perilaku pengurus untuk memuji target. Pujian bagi relawan juga dilontarkan ketika sesi sharing. Saat relawan selesai menceritakan pengalamannya, penanggung jawab selalu menyampaikan pujian kepada mereka. Tidak berhenti pada kegiatan rutin saja, saat acara bebas yang lebih kepada komunikasi antar personal atau kelompok-kelompok kecil, pengurus Sebung masih membiasakan diri untuk menyampaikan pujian sehingga relawan Sebung akan semakin nyaman berbincang dan terbuka dengan para pengurus atau anggota Sebung lainnya.

2) Kepercayaan

Pada komunitas Sebung, kepercayaan diberikan oleh pengurus Sebung ketika mereka sudah merasa relawan tersebut masuk kriteria yang sudah ditentukan. Hingga kini pengurus Sebung sudah memberikan kepercayaannya kepada relawan untuk mengelola kegiatan-kegiatan Sebung seperti menjadi penanggung jawab Sebung mingguan pada hari jumat, lalu kegiatan bulanan misalnya social experience di car free day Dago Bandung, sampai kegiatan tahunan misalnya Sebung Anniversary atau Sebung Qurban. Maka beberapa kegiatan Sebung selalu disertai para relawan sebagai panitia didalamnya.

3) Sertifikat Kegiatan

Sebung

memberikan apresiasi berbentuk fisik yang dapat menjadi simbol partisipasi para relawan dalam membantu kegiatankegiatan Sebung Bandung. Selain menambah rasa senang dan loyalitas relawan, sertifikat ini berguna untuk 
kepentingan relawan lainnya seperti kebutuhan pemenuhan keaktifan kegiatan bersertifikat sebagai syarat lulus mahasiswa atau pertukaran pelajar dan kebutuhan lainnya. Dengan begitu antara pengurus dan relawan menciptakan kondisi simbiosis mutualisme.

\section{Personal Appeal Tactics}

Florence Littauer pada Great Influencer (2018:12) mengatakan bahwa dalam diri manusia terdapat karakter atau kepribadian yang berbeda-beda, sehingga perasaan gamang pun akan muncul jika dalam menjalin suatu relasi dengan orang lain. Ketika seseorang telah menentukan yakin untuk menjalin suatu relasi dengan orang lain, maka timbul kedekatan personal dan kepercayaan antara satu dan lainnya. Maka dari itu mereka dapat saling mempersuasi satu sama lain.

Dengan melakukan sharing information antara relawan dan pengurus maka mereka saling mempercayai untuk terus bertahan dalam suatu komunitas. Langkah yang dilakukan oleh pengurus sendiri yaitu dengan selalu mengingatkan seluruh anggota Sebung Bandung pada platform group whatsapp. Pengumuman Sebung mingguan disebar melalui grup setiap Rabu malam. Sementara pengumuman lainnya disebar sesuai dengan kegiatan yang diadakan yaitu paling lambat tiga hari sebelum kegiatan. Lalu jika dilihat ada anggota Sebung yang sudah lama tidak mengikuti kegiatan selama lebih dari satu bulan, maka akan di hubungi secara jalur pribadi melalui chat whatsapp oleh divisi humas Sebung. Hasil yang didapati relawan menjadi loyal karena adanya rasa aman. Merekapun menerapkan kembali untuk melakukan sharing information sebagai wujud kontribusi mereka terhadap keberlangsungan komunitas sosial Sebung Bandung kedepannya.

\section{Exchange Tactics}

Amin pada Great Influencer (2018:59) mengatakan bahwa merasakan apa yang orang lain rasakan amat sangat sulit, membutuhkan perenungan, petualangan perasaan yang intens. Oleh karena itu, seseorang yang hidup didunia ini membutuhkan petualangan perasaan ke wilayah orang lain agar kepedulian pada orang lain semakin tajam. Pengurus Sebung Bandung menerapkan faktor exchange tactics ini kedalam hubungan antara pengurus dan relawan. Dengan adanya acara bebas setelah sharing session, anggota komunitas akan dengan leluasa bertukar pengalaman, kesenangan, pekerjaan dengan lebih intens. Pengurus Sebung secara sengaja menanamkan faktor ini agar antar anggota Sebung dapat menjadikan Sebung lebih dari sekedar komunitas namun dapat menjadi rumah kedua dan self healing. Pengurus Sebung Bandung membangun suasana melalui tiga topik yaitu utama yaitu food, love, dan problem. Topik food dan love menjadi gerbang untuk mencairkan suasana dalam suatu forum. Sementara topik problem mengantarkan anggota Sebung baik pengurus dan relawan kepada hubungan yang lebih intens lagi. Faktor ini menimbulkan beberapa hal dalam diri Relawan yaitu:

1) Similarity

Informan utama Sebung Bandung didominasi oleh kesamaan akan perasaan senasib yang timbul ketika masing-masing relawan merasakan ada kesamaan pada cerita 
yang disampaikan oleh mereka. Perasaan senasib itu menimbulkan hal-hal baru seperti rasa bersyukur, rasa aman dan rasa empati. Perasaan senasib yang dirasakan relawan Sebung sangat beragam dari mulai ranah keluarga, kepribadian, hubungan asmara, pekerjaan dan pendidikan. Mereka menemukan persamaan masalah dan akhirnya dapat saling belajar, menghargai dan memberi masukan satu sama lain.

2) Sikap Terbuka

Keempat Informan yang sudah bergabung dengan komunitas ini selama lebih dari satu tahun mengatakan mereka sudah terbuka dengan beberapa anggota Sebung yang mereka percaya. Sehingga mereka merasa aman dan nyaman ketika bercerita mengenai hal-hal yang menyenangkan maupun menyedihkan. Sementara satu informan utama mengatakan belum terbuka dengan satupun relawan maupun pengurus Sebung karena waktu yang belum cukup untuk ke tahap tersebut.

3) Self Healing

Sebung merupakan komunitas yang dapat menjadi wadah bagi relawan yang ingin menyembuhkan dirinya dari beban atau masalah yang dihadapinya. Mayoritas relawan sebung merupakan orang-orang yang mencari tempat untuk melarikan diri dari masalah yang mereka miliki. Faktor tersebut didorong karena kemampuan pengurus Sebung untuk menciptakan suasana yang nyaman dan waktu kegiatan pada malam hari yang membuat kegiatan menjadi hikmat dan penuh makna.

4) Keinginan Bertahan dalam Komunitas

Relawan akan bertahan dalam komunitas Sebung bukan dengan alasan untuk melakukan kebaikan dengan berbagi sebagai tujuan utamanya, namun untuk bertemu relawan dan pengurus Sebung lainnya. Relawan Sebung menganggap Sebung sebagai keluarga bagi mereka. Karena dengan mengikuti Sebung, mereka merasa menemukan kedamaian pada dirinya sendiri.

Faktor exchange tactics ini akhirnya membentuk sense of community atau perasaan memiliki terhadap komunitas Sebung Bandung. Perasaan ini akan mengakibatkan keinginan anggota untuk mempertahankan keberadaan komunitas dengan cara apapun. Salah satunya dengan memperlihatkan kontribusi mereka dalam menyemarakan kegiatan rutin komunitas. Sense of community memiliki empat elemen yang masing-masing elemennya sudah ada dan diterapkan pada komunitas Sebung Bandung. McMillan dan Chavis pada (Chavis, 2008) menyebutkan Keempat elemen tersebut yaitu:

1) Membership

Keanggotaan merupakan perasaan bahwa seseorang telah menginvestasikan diri sendiri untuk menjadi anggota dalam sebuah komunitas. Keanggotaan dalam sebuah komunitas memiliki batasan dalam komunitas yang membedakan anggota komunitas dengan yang bukan anggota komunitas, serta mengetahui siapa saja yang ada dalam komunitas tersebut. 
Keanggotaan yang menjadi pembeda antara kegiatan komunitas sosial Sebung Bandung dengan komunitas sosial lainnya terlihat dari kegiatan yaitu greeting and sharing. Lalu untuk anggota komunitas sendiri, anggota Sebung memiliki kaos dan tote bag sebagai identitas anggota yang membedakan anggota Sebung dan anggota komunitas lain.

2) Influence

Pengaruh adalah kekuatan yang dimiliki individu untuk mempengaruhi anggota lain dan kekuatan komunitas untuk memengaruhi individu. Upaya saling memengaruhi antara anggota dan komunitas sudah ditampilkan dari seluruh rangkaian kegiatan Sebung Bandung dari briefing, turun ke jalan, sharing session, hingga acara bebas.

3) Integration and Fulfillment of Needs Integrasi dan pemenuhan kebutuhan adalah perasaan bahwa kebutuhan anggota akan dipenuhi oleh sumber daya yang diterima melalui keanggotaan mereka dalam suatu kelompok. Semua anggota komunitas Sebung Bandung saling berintegrasi dan melalui komunitas ini, seluruh anggota merasa terpenuhi kebutuhannya. Ditunjukan dengan Informan utama yang mengatakan bahwa alasan untuk mengikuti kegiatan Sebung bukan sekedar berbagi. Dan mengikuti kegiatan Sebung merupakan suatu kebutuhan yang sudah menjadi rutinitas mereka sebagai relawan Sebung.

4) Shared Emotional Connection

\begin{abstract}
Hubungan emosional bersama dalam suatu komunitas yang terbentuk dari interaksi positif, berbagi cerita dan pengalaman yang dilakukan bersama. Semakin banyak orang berinteraksi, semakin besar kemungkinana mereka untuk membentuk hubungan yang erat, yang kemudian mengarah ke ikatan yang lebih kuat.
\end{abstract}

Anggota komunitas Sebung Bandung baik dari pengurus hingga relawan memiliki keharusan untuk saling berbagi perasaan dan memiliki ikatan emosional. Ditunjukan pada kegiatan sharing dan acara bebas yang membuat mereka saling terbuka dan empati. Komunitas Sebung Bandung ini bisa bertahan karena anggota komunitasnya sudah memiliki keempat elemen yang sudah disebutkan.

Kelima faktor yaitu rational persuasion, consultation tactics, ingratiation tactics, personal appeals tactics dan exchange tactics pada implementasi komunikasi persuasi dalam mempertahankan loyalitas komunitas Sebung Bandung, menjadi efektif karena membentuk komunitas yang berkontribusi aktif dengan berpartisipasi dalam seluruh kegiatan Sebung Bandung. Pada akhirnya terbentuk sense of community pada anggota komunitas yang menciptakan loyalitas relawan komunitas Sebung Bandung untuk mempertahankan keberlangsungan komunitas Sebung kedepannya.

\section{Kesimpulan}

Penerapan teknik-teknik yang membangun komunikasi persuasi yang diterapkan oleh pengurus Sebung Bandung dalam mempertahankan loyalitas relawan 
komunitas sosial Sebung Bandung adalah dengan 1) rational tactics, yaitu mempersuasi dari kesan pertama bertemu yang diterapkan pada kegiatan briefing, dengan mengarahkan relawan dilandasi oleh alasan dan data yang logis dan berupa fakta, 2) consultation tactics, yaitu mempersuasi dengan memberi sarana untuk mengembangkan kemampuan relawan yang diterapkan pada kegiatan sharing session, dengan mengembangkan kemampuan public speaking, mendengarkan, berempati dan merubah persepsi, 3) ingratiation tactics, yaitu mempersuasi dengan memberikan apresiasi yang diterapkan pada seluruh rangkaian kegiatan Sebung, dengan memberikan pujian, kepercayaan, serta sertifikat kegiatan, 4) personal appeal tactics, yaitu mempersuasi dengan kedekatan personal yang diterapkan pada sharing information, dengan mengajak teman terdekat untuk bertahan dalam komunitas, 5) exchange tactics, yaitu mempersuasi dengan kedekatan personal yang lebih dalam yang diterapkan pada kegiatan sharing dan acara bebas, dengan menimbulkan similarity, sikap terbuka, self healing, dan keinginan bertahan dalam komunitas.

Kelima teknik tersebut menimbulkan sense of community pada anggota komunitas Sebung Bandung meliputi membership, influence, integration and fulfillment of needs, dan shared emotional connection. Setelah sense of community terbentuk, relawan komunitas Sebung memiliki keinginan untuk berkontribusi dengan berpartisipasi dalam setiap kegiatan-kegiatan Sebung Bandung dan pada akhirnya membentuk loyalitas relawan komunitas sosial Sebung Bandung.

\section{Daftar Pustaka}

\section{Buku:}

Arifin, Zainal. (2012). Penenlitian Pendidikan Metode dan Paradigma Baru. Bandung: Remaja Rosda Karya.

Chavis, D.M Lee. (2008). The Sense of Community (SCI) Revised: The Reliability and Validity of The SCI. Lisboa: International Community Psychology Conference

Ibrahim. (2015). Metodologi Penelitian Kualitatif. Bandung: Alfabetha.

Morissan. (2013). Teori Komunikasi. Bogor: Ghalia Indonesia.

Sudarsana. (2016). 116 Kiat Mempertajam Kinerja Anak Buah. Bandung: Laksana.

Soemirat, Soleh \& Suryana, Asep. (2014). Komunikasi Persuasif. Banten: Universitas Terbuka.

Soemirat \& Suryana, Soleh \& Asep. (2016). Komunikasi Persuasif. Tangerang Selatan: Universitas Terbuka.

Wijaya, Cahyo Satria. (2018). Great Influencer. Yogyakarta: Bright Publisher.

\section{Artikel Jurnal:}

Asih dan Pratiwi. (2010). Perilaku Prososial ditinjau dari Empati dan Kematangan Emosi. Jurnal Psikologi, Volume 1 No.1. Kudus: Universitas Muria Kudus.

Leksono, Jati Widyo. (2014). Pendekatan Saintifik Pada Kurikulum 2013 untuk Meningkatkan Kemampuan Berpikir secara Kritis Siswa Prosiding Konfensi Nasional Asosiasi Pendidikan Teknologi dan Kejuruan.

\section{Artikel dalam Internet:}


Jurnal Komunikasi Universitas Garut: Hasil Pemikiran dan Penelitian Vol. 7, No. 1, April 2021

Halaman 606-616

Nitisemito. (2013). Pengertian Disiplin Kerja didalam Organisasi. Tersedia: http://www.pusattesis.com/. [Akses: 15 September 2019].

Rosadi, D. (2016, 27 Februari). Ridwan Kamil Minta Komunitas Bantu Pemkot Bandung Hadirkan Perubahan. Merdeka [Online], halaman 1 , Tersedia: https://bandung.merdeka.com/komu nitas/ 